\title{
Production of the Bacillus licheniformis SubC protease using Lactococcus lactis NICE expression system
}

\author{
Aleksandra M Mirończuk ${ }^{1,2}$, Anna Krasowska², Anna Murzyn², Małgorzata Płachetka ${ }^{2}$ and Marcin Łukaszewicz ${ }^{1,2,3^{*}}$
}

\begin{abstract}
In this work the subC gene from Bacillus licheniformis encoding subtilisin was cloned into the nisin-controlled expression (NICE) vectors (pNZ8048 and pNZ8148) with or without the signal peptide SP Usp45 directing extracellular secretion via Sec machinery. Extracellular protease production and activity was tested using Lactococcus lactis NZ9000 as host, which could be used for rennet production. The efficiency of protein production was tested using purified nisin and the supernatant of L. lactis NZ970 nisin producer. Similar results were obtained for $1 \mathrm{ng} / \mathrm{ml}$ nisin and 10000 diluted supernatant. SP Usp45 signal peptide effectively directed extracellular localization of active and stable protease. SubC signal for extracellular localization in B. licheniformis, was also recognized by L. lactis Sec pathway, although with lower efficiency, as shown by a 3-fold lower protease activity in the medium. Protease production and activity was optimized using parameters such as induction time, nutrients (glucose, casitone) supplementation during growth or protease stabilization by calcium ions. The results were also verified in fed-batch bioreactor for further scale-up of the expression system.
\end{abstract}

Keywords: Lactic acid bacteria, Lactococcus lactis, Nisin-controlled expression system, NICE, Bacillus licheniformis, SubC protease

\section{Introduction}

Lactococcus lactis is a Gram-positive, lactic acid bacterium that is commonly used in traditional food industries such as in cheese and butter production. In addition, it is increasingly used in modern biotechnological applications. Many recent studies have investigated the physiology and genetic of this bacterium, therefore a wide variety of genetic tools have been developed. Nowadays several genomes of $L$. lactis strains are completely sequenced (Bolotin et al. 2001; Siezen et al. 2010; Wegmann et al. 2007). Genetic accessibility and the ease of working with this organism have led to extensive study on heterologous protein expression in L. lactis. Since L. lactis is generally recognized as safe (GRAS) it

\footnotetext{
* Correspondence: marcin.lukaszewicz@uni.wroc.pl

'Department of Biotechnology and Food Microbiology, Wrocław University of Environmental and Life Sciences, Chełmońskiego 37/41, Wrocław 51-630, Poland

${ }^{2}$ Department of Biotransformation, Faculty of Biotechnology, University of Wroclaw, Przybyszewskiego 63-77, Wroclaw 51-148, Poland Full list of author information is available at the end of the article
}

could be used for large-scale production of heterologous proteins (Mierau et al. 2005a; Morello et al. 2008). Most of the laboratory scale examples consist of intracellular expression (Blatny et al. 2003; Kunji et al. 2003) or cell wall bound enzymes (Cibik et al. 2001; Miyoshi et al. 2002; Nouaille et al. 2003). Much less in known about extracellular production of the proteins in L. lactis, moreover the protein yield might differ significantly and are strongly case-dependent (Mierau \& Kleerebezem 2005).

In 1995 Kuipers et al. (1995) published a study on the autoinduction of the expression of nisin in lactococci. This study allowed for the construction of a food grade expression system based on the regulation mechanism of the nisinA operon of L. lactis (Platteeuw et al. 1996), named NICE (nisin-controled gene expression). In this operon the gene product, a small 34 amino acid bacteriocin, induces its own transcription at very low concentrations $(0.5-5 \mathrm{ng} / \mathrm{mL}$ ) (Kuipers et al. 1998). In this system, nisin induces the regulatory cascade starting with binding to the membrane-bound receptor NisK. Next, the phosphate group from the activated NisK is 
transferred to the intracellular response regulator NisR, activating this regulator. Subsequently, NisR, induces the nisin operon at the promoter nisA (Kleerebezem \& Quadri 2001). The NisA promoter controls the expression of the genes involved in the nisin biosynthesis (or the gene of interest). Genes of this regulatory system have been inserted in a suitable host strain L. lactis NZ900. The nisin-producing strain L. lactis NZ9700 secretes the nisin into the medium (Kuipers et al. 1995).

It was shown that the NICE system can be developed to "food-grade" production of heterologous protein, by replacing the antibiotic resistant gene by another selectable marker (Olempska-Beer et al. 2006), for example $l a c F$, which has been deleted from the host strain, and is essential for growth on lactose (Mierau et al. 2005b). Although for large-scale production nisin usage remains costly, a good alternative is the addition of NZ9700 supernatant. The NICE system is often used in the laboratories for research, while the data on large-scale application of the NICE system for secreted proteins is still very limited. Up to now, only a few reports present usage of this system in industry (Mierau et al. 2005a; Mierau et al. 2005b; Berlec \& Strukelj 2009), moreover, efficient systems for the industrial scale production of secrete heterologous proteins have never been described.

In this study, we describe the production of secrete heterologous protein SubC in L. lactis using the NICE expression system. SubC is the industrially important Carlsberg-type subtilisin (Jacobs 1995) produced by Bacillus licheniformis. Bacterial subtilisins are multipurpose alkaline proteases that are frequently used in industry (Gupta et al. 2002): common variants include subtilisin from $B$. amyloliquefaciens, highly alkalophilic $B$. lentus or from B. licheniformis (Rao et al. 1998; von der Osten et al. 1993). Furthermore, Flavobacterium also produces subtilisin (Morita et al. 1998). Interestingly, almost two-third of commercial proteases produced in the world originate from microorganisms (Kumar \& Takagi 1999; Tremacoldi et al. 2004). Microbial proteases are classified into different groups, according to their activity in acid, neutral or alkaline conditions, and on the characteristics of the active site group of the enzyme (Saeki et al. 2007). Subtilisin-like serine proteases are usually secreted extracellulary for searching nutrients (Aehle et al. 2009). One of the features of this class of proteases (subtilases) is an aromatic or hydrophobic residue, such as leucine, tyrosine or phenylalanine. The highest proteolytic activity is around $\mathrm{pH} 10$, with a molecular weight range of $15-40 \mathrm{kDa}$ and an isoelectric point around $\mathrm{pI}$ 9. Moreover, the native form of SubC remains fully stable up to $60^{\circ} \mathrm{C}$ (Hirata et al. 2003) and it possesses two calcium binding site(s), therefore bound $\mathrm{Ca}^{2+}$ contributes to enzyme stability (Briedigkeit \& Frömmel 1989).
Our main objective in this study was an improvement of the expression condition for secreted heterologous protein production and the comparison of the gene expression efficiencies using two different NICE expression plasmids. We compared two different NICE vectors and the ability of L. lactis for secretion of heterologous protein. The activity of protease production was tested on milk plates. Subsequently the proteolytic activity assays were performed to investigate the functionality of the secreted protease in the medium. In addition, we present modification of the NICE system, by changing the growth conditions, the induction point, and by extending the logarithmic phase growth of bacteria by supplying further nutrients.

\section{Methods}

\section{Strains and growth conditions}

The strains and plasmids used in this study are listed in Table 1.

Lactococcus lactis strains were grown in M17 broth (Terzaghi \& Sandine 1975) supplemented with 0.5\% glucose (GM17). Additionally, for strains carrying plasmid, medium was supplemented with chloramphenicol $\left(5 \mu \mathrm{g} \mathrm{mL}^{-1}\right)$. Cultures were incubated at $30^{\circ} \mathrm{C}$. If required, medium was supplemented with $10 \%$ milk or different concentrations of $\mathrm{CaCl}_{2}, \mathrm{MnCl}_{2}, \mathrm{MgCl}_{2}$ and $\mathrm{MgSO}_{4}$. Additionally, samples were supplemented with $5 \mu \mathrm{g} \mathrm{mL}^{-1}$ chloramphenicol, if required. Bacterial growth was determined by measuring the optical density (OD) at $600 \mathrm{~nm}$. The cultures were inoculated at optical density 0.1 or at a different point if mentioned. At the beginning of the incubation or when the bacterial growth reached the required cell density, the cultures were stimulated to produce protease by the addition of nisin (Sigma) or by the dilutions of the culture supernatant of the nisin producing strain L. lactis NZ9700 (the range of concentrations or dilutions indicated in Results). The

Table 1 Strains used in this study

\begin{tabular}{lll}
\hline Strain/plasmid & Relevant characteristics & Reference \\
\hline ATCC 10716 & B. licheniformis & Laboratory stock \\
NZ9000 L. lactis & MG1363 pepN::nisRK & (Kuipers et al. 1998) \\
NZ9700 L. lactis & Nisin producer & (Kuipers et al. 1995) \\
pNZ8048 & Cm $^{\text {R }, \text { inducible expression }}$ & (Kuipers et al. 1998) \\
& vector containing the & \\
& nisA promoter & \\
pNZ8148 & PnisA, CmR; replicon of & NIZO \\
& rolling circle plasmid pSH71, & \\
& basic NICE vector, derivative & \\
pNZ45 & pN pNZ848 & \\
& under nisA promoter & This study \\
pNZ45subC & pNZ45 carrying subC gene & This study \\
pNZ48subC & pNZ8148 carrying subC gene & This study \\
\hline
\end{tabular}


batch cultivations were performed in a 5-1 stirred-tank reactor (Labfors 3; Infors, Swizerland) with a working volume of $1.5 \mathrm{l}$ at $30^{\circ} \mathrm{C}$. The stirrer speed was adjusted to $60 \mathrm{rpm}$ and the $\mathrm{pH}$ was maintained automatically at 7.0 by the addition of $1 \mathrm{M} \mathrm{NH} \mathrm{NH}_{4} \mathrm{OH}$. The cultures were grown in the M17 medium supplemented with 10\% milk, $0.5 \%$ glucose and chloramphenicol $\left(5 \mu \mathrm{g} \mathrm{mL}{ }^{-1}\right)$; induction at optical density 0.2 . The samples were taken every 2 hours.

\section{Construction of pNZ45subC, pNZ48subC}

It was shown, that Usp45 signal peptide of L. lactis enables secretion of the heterologous protein via the Sec pathway (Morello et al. 2008) in L. lactis strains (van Asseldonk et al. 1993). Therefore, to express the secretion protein, first the usp 45 peptide signal was amplified with Usp-45-F (5'-GCGC CCATGGGGAAAAAAAA GATTATCTCAGCTATTTTAATG-3') and Ups-45-R (5'-CGCCGCATGCCCCGGGTGTGT CAGCGTAAAC-3') primers. Subsequently the 120 bp PCR product was cloned into the NcoI/SphI sites of pNZ8040 (Kuipers et al. 1998), resulting in pNZ45. After amplification of B. licheniformis subC gene with subC- F (5'-ATGAG GAAAAA GAGTTTTTG-3') and subC- R (5'-CGCG TCTAGATTATTGAGCGGCAGCTTC-3') primers, the 1139 bp PCR fragment was digested with XbaI and cloned into the pNZ45 digested with SmaI and XbaI, yielding in pNZ45subC. The SP Usp45 fragment is supposed to be cleaved during secretion of protein via Sec translocon into the environment (Mierau \& Kleerebezem 2005). Finally, for the control, subC gene was fused translationally to the Nisin-inducible promoter $\mathrm{P}_{\text {nisA }}$ of pNZ8148 (lack of SP Usp45). To overexpress SubC in pNZ8148 (Mierau \& Kleerebezem 2005), the gene was amplified with subC-48-F (5'-GCCGCCATGGGGAT GATGAGGAAAAAGAG-3') and subC-48-R (5'-CGCG GCATGCTTATTGAGCGGCAGCTTC-3') primers. The PCR was digested with $\mathrm{NcoI}$ and SphI and ligated into the corresponding sites of pNZ8148, resulting in pNZ48subC. Transformation of L. lactis NZ9000 was achieved by electroporation using Gene pulser (Biorand Laboratories) as described by Leenhouts an Venema (Leenhouts \& Venema 1993).

\section{Expression of SubC in L. lactis and sample preparation}

L. lactis NZ900 carrying pNZ45subC or pNZ48subC was cultivated in M17 medium (Difco) containing 0.5\% glucose and $5 \mu \mathrm{g} \mathrm{mL}{ }^{-1}$ chloramphenicol. To test for the expression of SubC L. lactis was grown in $10 \mathrm{ml}$ cultures, diluted from overnight culture to an $\mathrm{OD}_{600}$ of 0.1 at $30^{\circ} \mathrm{C}$. The samples were induced at start point with NisinA (1:10000 dilution of the culture supernatant of the nisin producing strain L. lactis NZ9700) and the cultures were incubated for 24 hours. $1.5 \mathrm{~mL}$ of culture was spun down $\left(14000 \mathrm{rpm}, 10 \mathrm{~min}, 4^{\circ} \mathrm{C}\right)$ and $500 \mu \mathrm{L}$ of supernatant was transferred into a fresh tube. Next, the same volume of cold 10\% TCA (trichloroacetic acid) was added. The sample was incubated for $5 \mathrm{~min}$ at $-20^{\circ} \mathrm{C}$ and subsequently was spun down $\left(14000 \mathrm{rpm}, 10 \mathrm{~min}, 4^{\circ} \mathrm{C}\right)$ then the supernatant was discarded. The pellet was washed with $500 \mu \mathrm{L}$ of cold acetone and spun down under the same conditions. The pellet was resuspended in $20 \mu \mathrm{L}$ PBS buffer (137 mMol/L NaCl; $1.76 \mathrm{mMol} / \mathrm{L} \mathrm{KH}_{2} \mathrm{PO}_{4} ; 8.1$ $\mathrm{mMol} / \mathrm{L} \mathrm{Na}_{2} \mathrm{HPO} 4 \times \mathrm{H}_{2} \mathrm{O} ; 2.7 \mathrm{mMol} / \mathrm{L} \mathrm{KCl}$. The effect of heterologous protein expression in differently supplemented M17 medium, was compared by $12 \%$ sodium dodecyl sulfate-polyacrymide gel electrophoresis (SDSPAGE) followed by Coomassie staining. The samples were diluted 2x SDS sample buffer and aliquots of $10 \mu \mathrm{l}$ were loaded per lane. Molecular masses were estimated using PageRuler ${ }^{\mathrm{TM}}$ Prestained Protein Ladder (Fermentas).

\section{Proteolytic activity assay}

Proteolitic activity was assayed using $0.5 \%$ casein (Sigma) as a substrate, dissolved in $50 \mathrm{mM}$ Tris- $\mathrm{HCl}$ buffer at $\mathrm{pH}$ 10. Tests were performed in final volume of $800 \mu \mathrm{L}$ containing $500 \mu \mathrm{L} 0.5 \%$ casein, $200 \mu \mathrm{L} 50 \mathrm{mM}$ Tris- $\mathrm{HCl}$ buffer $\mathrm{pH} 10$ and $100 \mu \mathrm{L}$ of supernatant from the tested culture. Samples were incubated at $50^{\circ} \mathrm{C}$ for $30 \mathrm{~min}$. Reaction was stopped by the addition of $500 \mu \mathrm{L}$ of $10 \%$ trichloroacetic acid. Control samples were assayed similarly but the supernatants were added after the addition of trichloroacetic acid. Samples were centrifuged for $10 \mathrm{~min}$ at $15000 \mathrm{rpm}$ at $4^{\circ} \mathrm{C}$. The absorbance of free tyrosine was measured at $275 \mathrm{~nm}$ using Thermo Electron Corporation Evolution 600 UV-Visible Spectrophotometer. To calculate the proteases activity, an extinction curve for tyrosine was prepared. Various concentrations of tyrosine in $50 \mathrm{mM}$ Tris buffer at $\mathrm{pH} 10$ were incubated as treated samples. One unit of enzyme activity was defined as the amount of enzyme that releases $1 \mu \mathrm{g}$ tyrosine per 1 min under these conditions.

\section{Amino acid sequence analysis}

Proteins from the culture supernatant were salted out using $50 \%$ ammonium sulfate and visualized by SDS-PAGE gel electrophoresis. Then, proteins were transferred on the PVDF membrane and the $38-\mathrm{kDa}$ band (containing subtilisin C) was chosen for sequencing. Amino acid sequencing was performed by using Edman degradation.

\section{Results}

\section{Overexpression of SubC in L. lactis by nisinA or} supernatant of NZ9700

In this report, two standard vectors, pNZ8148 (Kumar \& Takagi 1999) and pNZ8048 (Mierau et al. 2005b), were 
used for direct expression of B. licheniformis SubC protein (Hirata et al. 2003). Two constructs pNZ45subC or pNZ48subC (for details see Material and Methods) were introduced into NZ900 L. lactis strain. For the induction of heterologous protease, various growth conditions such as the induction time point and the range of nisin concentrations have been investigated. The activity of the supernatant of pNZ45subC or pNZ48subC was tested against casein substrate (see material and methods). Casein was used for proteolytic assays, since casein is the most frequently used substrate for protease activity under neutral and alkaline conditions.

Initially tests were performed on the GM17 plates supplemented with $10 \%$ milk, consequently the same conditions were used during growth in liquid medium. The samples were induced at the beginning of growth at the optical density 0.1. Protein expression was induced by the addition of nisinA in the final concentration of $0.1 \mathrm{ng} \mathrm{mL}^{-1}, 0.5 \mathrm{ng} \mathrm{mL}^{-1}, 1 \mathrm{ng} \mathrm{mL}^{-1}, 2 \mathrm{ng} \mathrm{mL}^{-1}, 5 \mathrm{ng} \mathrm{mL}^{-1}$ and $10 \mathrm{ng} \mathrm{mL} \mathrm{m}^{-1}$. The induced and non-induced cells were harvested after $24 \mathrm{~h}$, and the proteolytic activity assay was performed. The results are listed in Table 2 . The highest proteolytic activity was observed after induction of $1 \mathrm{ng} / \mathrm{mL}$, in all non-induced strains proteolytic activity was close to zero. To verify the optimal conditions for protein expression, a range of nisin and the NZ9700 supernatant concentrations was tested $(100 \times$ dilution to $200000 \times$ dilution of the culture supernatant of the nisin producing strain L. lactis NZ9700). The results are listed in Table 3. All induced cultures showed different ranges of enzymatic activity; in all non-induced cultures the values of proteolytic activity was below 1 . The highest proteolytic activity was obtained when $10000-20000$ diluted supernatant of L. lactis NZ9700 was used. This data showed that SubC was secreted into the growth medium and the protein remained active. Similar activity was observed when cultures were induced with $1 \mathrm{ng} \mathrm{mL}{ }^{-1}$ purified nisinA (see Table 2) or $10000-20000$ diluted supernatant of NZ9700. Since the use of purified nisinA at industry scale might be costly, in further experiments for the induction the supernatant of the NZ9700 strain was added. The

Table 2 The proteolytic activity of L. lactis NZ9000 carrying pNZ45subC

\begin{tabular}{ll}
\hline $\begin{array}{l}\text { Concentration of nisinA used } \\
\text { for induction }\left(\mathbf{n g ~ m}^{-1}\right)\end{array}$ & $\begin{array}{l}\text { Proteolytic } \\
\text { activity (U/L) }\end{array}$ \\
\hline 0.1 & $25.5 \pm 5.9$ \\
0.5 & $56.7 \pm 16.6$ \\
1.0 & $142.7 \pm 6.8$ \\
5.0 & $73.7 \pm 3.4$ \\
10.0 & $72.6 \pm 2.0$ \\
\hline
\end{tabular}

Samples were taken in 24 hours after induction.
Table 3 The proteolytic activity of L. lactis NZ9000 carrying pNZ45subC

\begin{tabular}{ll}
\hline $\begin{array}{l}\text { Dilutions of NZ9700 supernatant } \\
\text { used for induction }\end{array}$ & $\begin{array}{l}\text { Proteolytic } \\
\text { activity (U/L) }\end{array}$ \\
\hline Non induced & $0.84 \pm 0.1$ \\
$100 \times$ & $3.0 \pm 0.3$ \\
$1000 \times$ & $76.1 \pm 5.9$ \\
$10000 \times$ & $148.5 \pm 0.7$ \\
$20000 \times$ & $146.9 \pm 5.4$ \\
$40000 \times$ & $105.0 \pm 2.8$ \\
$60000 \times$ & $128.1 \pm 1.8$ \\
$100000 \times$ & $28.5 \pm 0.8$ \\
$200000 \times$ & $8.9 \pm 3.9$ \\
\hline
\end{tabular}

Samples were taken in 24 hours after induction.

samples were collected for the proteolytic assays after 24 hours after induction.

Up to now, many reports have described studies of protein production using NICE expression systems induced at the midlog growth phase or at high OD, however, none of them tested the induction at start point (Mierau et al. 2005a; Maischberger et al. 2010). Therefore, to simplify protein expression, we have compared the proteolytic activity of samples induced during inoculation at $\mathrm{OD}_{600} 0.1$ with induction at $\mathrm{OD}_{600} 0.7$ (data not shown). Interestingly, we have observed similar activity, when the cultures were induced at $\mathrm{OD}_{600} 0.7$, however, only in samples supplemented with $10 \%$ milk. Most likely, the presence of calcium in milk contributes to the stability of secreted SubC. Interestingly, after a long time in extracellular environment (up to $48 \mathrm{~h}$ at $30^{\circ} \mathrm{C}$ ), SubC remained stable and was active. Moreover, an induction with NZ9700 supernatant at the start point allows for simpler use of the NICE system at industrial scale.

\section{Signal peptide - extracellular expression}

The same experiment for the pNZ48subC (construct lacking SP Usp45) was performed. Noticeably, the enzymatic activity of L. lactis strain lacking the signal peptide was around three times lower than that observed for the pNZ45subC strain (see Table 4). As mentioned before, SubC is an extracellular protease, which possesses its own signal peptide, and is secreted via Sec

Table 4 The proteolytic activity of L. lactis NZ9000 carrying pNZ45subC or pNZ48subC

\begin{tabular}{llll}
\hline L. lactis vectors & Proteolytic activity (U/L) & \\
\cline { 2 - 4 } & Non induced & nisinA 1 $\mathrm{ng} / \mathrm{mI}$ & $\begin{array}{l}10000 \times \text { diluted } \\
\text { NZ9700 supernatant }\end{array}$ \\
\hline pNZ45subC & $0.84 \pm 0.2$ & $142.7 \pm 6.7$ & $148.5 \pm 0.7$ \\
pNZ48subC & $0.84 \pm 0.1$ & $46.9 \pm 16.3$ & $41.6 \pm 8.1$ \\
\hline
\end{tabular}

Samples were taken in 24 hours after induction. 
machinery in B. licheniformis. In silico analysis showed a high homology of $\mathrm{SeC}$ transporters L. lactis and B. licheniformis: $74 \%$ for SecA, $64 \%$ for SecE and $67 \%$ for SecY. This explains the high level of active protease in the medium, however it is still lower in comparison with construct having native lactococcal signal peptide. To confirm this hypothesis SubC isolated from the medium was sequenced. The amino acids sequencing showed the presence of two subtilisins forms: immature (prosubtilisin) and mature (Figure 1). Thus, both signal peptides were properly cleaved during secretion, although signal peptide from Bacillus resulted in lower accumulation of protease in the extracellular medium. Therefore, for the further experiments $L$. lactis carrying pNZ45subC was used.

\section{Medium preferences}

Proteolytic assays were performed for the strains grown on GM17 and GM17 supplemented with 10\% milk (both supplemented with chloramphenicol). The highest proteolytic activity was observed during the growth on GM17 with 10\% milk. The growth on simple GM17 did not lead to the highest enzymatic activity of the culture under induction (see Figure 2), which might suggest that the secreted protease is not stable or not active under these conditions. SubC possesses two calcium binding sites assisting enzyme stability (Briedigkeit \& Frömmel 1989). The presence of milk in the medium could cause difficulties during the purification process of the enzyme on an industrial scale in the future. Therefore milk was replaced by different elements that are known to be present in it. To verify this thesis, different concentrations $(0.5 \mathrm{mM}-5 \mathrm{mM})$ of $\mathrm{CaCl}_{2}, \mathrm{MnCl}_{2}, \mathrm{MgCl}_{2}$ and $\mathrm{MgSO}_{4}$ were added to GM17. The samples were collected under the same conditions as described for milk; subsequently the proteolytic assays were performed. The results are presented in the Figure 2 and Figure 3.
subC

KKKIISAILMSTVILSAAAPLSGVYADT 28

SUbC RKKSFWLGMLTALMLVFTMAFSDSASAAQPAKNVEKDYIVGFKSGVKTASVKKDIIKESG 60

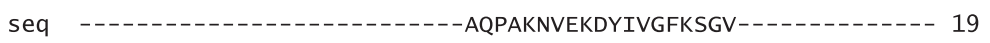

SUbC GKVDKQFRIINAAKAKLDKEALEEVKNDPDVAYVEEDHVAHALAQTVPYGIPLIKADKVQ 120

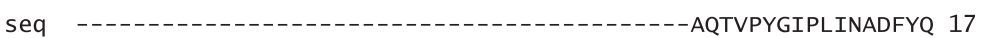

SUbC AQGYKGANVKVAVLDTGIQASHPDLNVVGGASFVAGEAYNTDGNGHGTHVAGTVAALDNT 180

seq AV--_-_- 19

SUbC TGVLGVAPNVSLYAVKVLNSSGSGSYSGIVSGIEWATTNGMDVINMSLGGPSGSTAMKQA 240

seq

SUbC VDNAYARGVVVVAAAGNSGSSGNTNTIGYPAKYDSVIAVGAVDSNSNRASFSSVGAELEV 300

seq

SUbC MAPGAGVYSTYPTSTYATLNGTSMASPHVAGAAALILSKHPNLSASQVRNRLSSTATYLG 360

seq

sub SSFYYGKGLINVEAAAQ 377

seq

Figure 1 The two 19-aa sequences obtained with Edman degradation ("seq") compared to the subtilisin C sequence with signal peptide usp45 ("subC"). Underlined - signal peptide usp45; bold - native signal peptide from B. licheniformis; grey-coloured - proregion. 


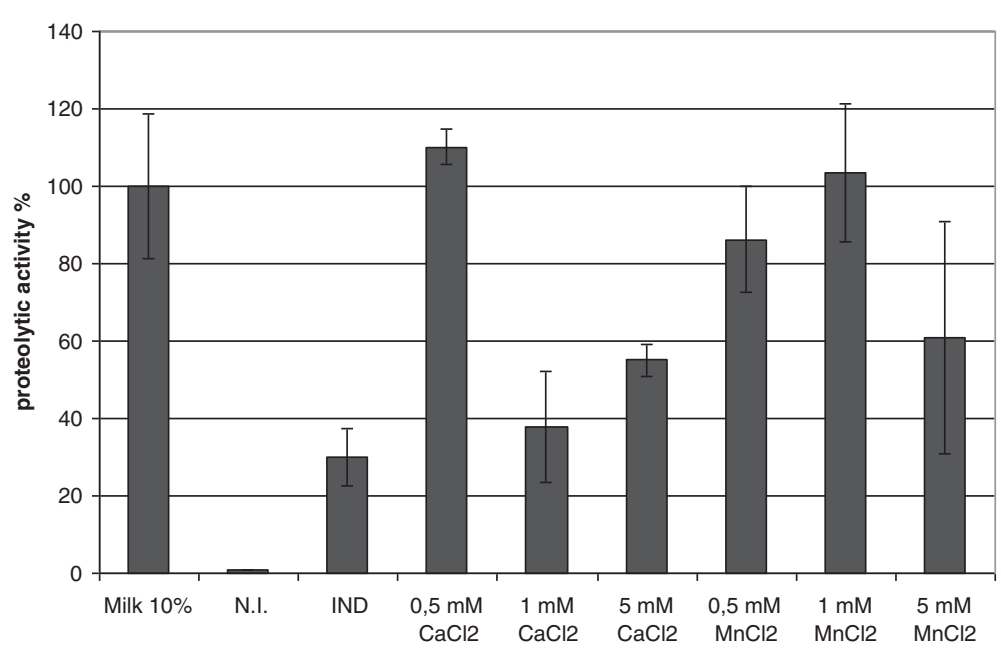

Figure 2 The proteolytic activity of $L$. lactis carrying pNZ45subC tested in $\mathbf{2 4}$ hours after induction. Strains were grown in GM17 medium, supplemented as indicated in the figure. The samples were induced at $\mathrm{OD}_{600} 0.1$ with 10000 NZ9700 supernatant. All data are mean values of three independent experiments; error bars indicate standard deviation.

Interestingly, data showed that adding into the medium two positive ions results in an enhanced level of proteolytic activity in comparison with GM17 without supplements; however for magnesium and manganese the activity is lower than in GM17 medium supplemented with $10 \%$ milk. Moreover, the highest proteolytic activity was obtained in a medium supplemented with $0.5 \mathrm{mM} \mathrm{CaCl}{ }_{2}$. The activity was about $10 \%$ higher than control supplemented with milk. To verify if the results obtained were caused by different amounts of protein retained in the medium, the samples of supernatants were collected and visualized on the SDS-PAGE gel (Figure 4). As is shown on the picture, non-induced samples possess many additional bands (residues from medium), while in all induced samples the number of bands is limited, this is most probably the effect of the protease activity. The expected size of SubC is $39 \mathrm{kDa}$, the corresponding band is present in all induced samples. Noticeably, the yield of the SubC protein in all induced samples seems to be the same. This data suggests that protein is produced and secreted, however measured activity depends mostly on calcium.

Next, different media that were previously shown to give higher yields of protein expressed by $L$. lactis (Mierau et al. 2005a; Berlec \& Strukelj 2009) were tested for SubC production. The same experiment as described

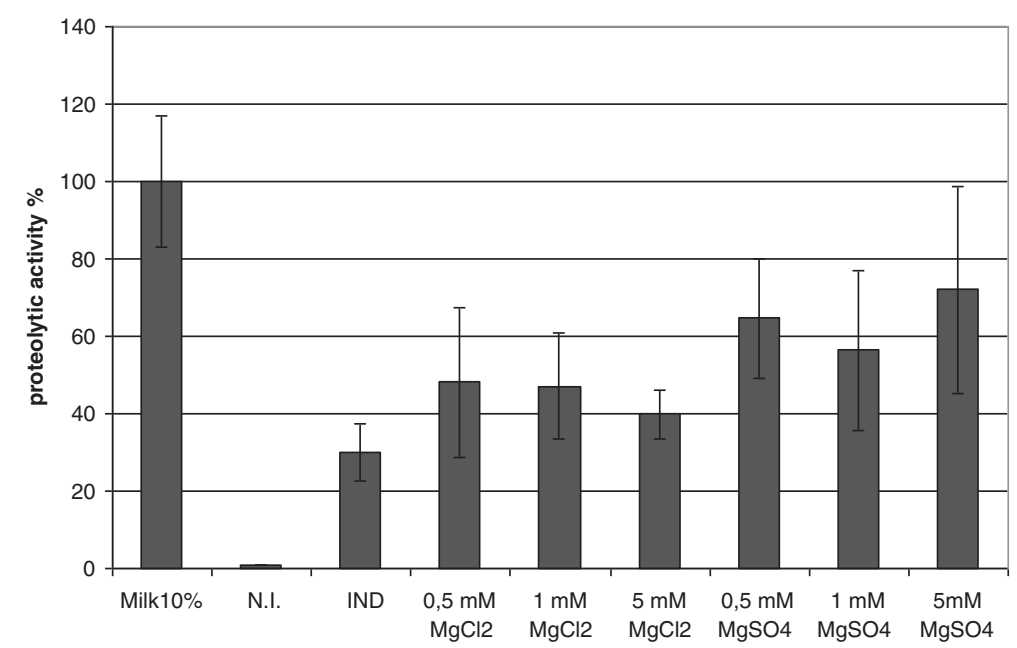

Figure 3 The effect of magnesium on the SubC proteolytic activity. L. lactis pNZ45subC grown in GM17 supplemented with chloramphenicol and magnesium compounds as mentioned on the picture. Samples were induced at OD 6000.1 with 10000 NZ9700 supernatant. The samples were taken in 24 hours after induction. 


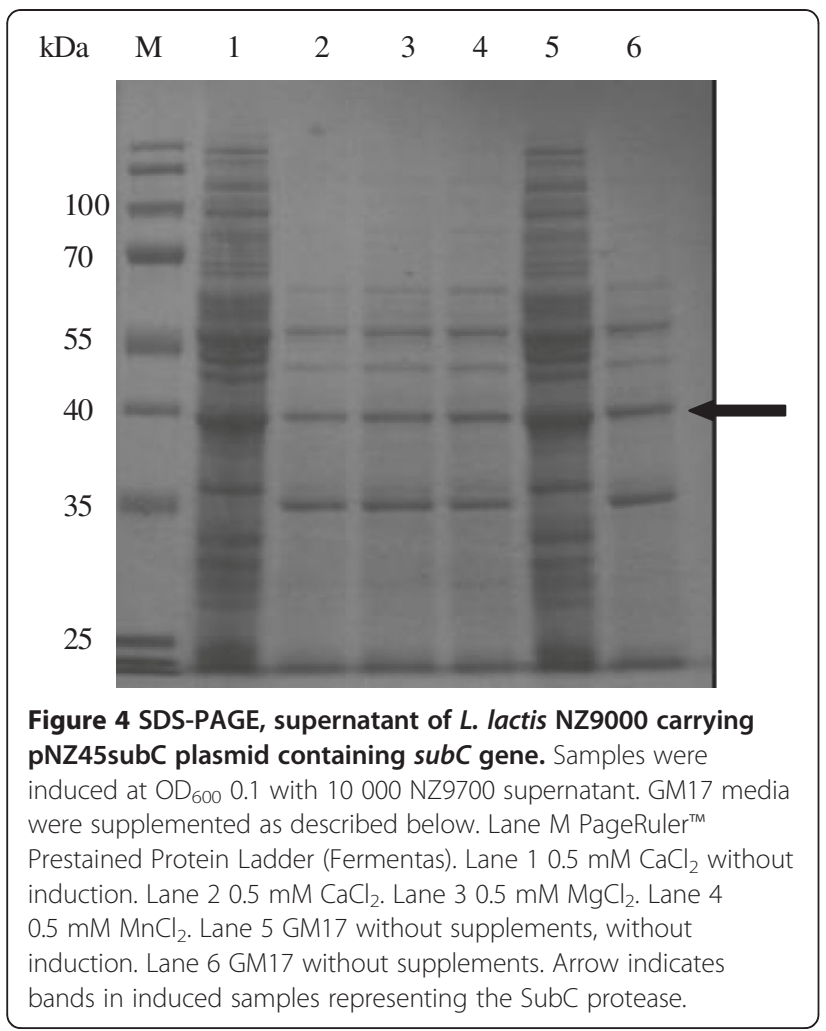

before was performed for new media. None of them showed higher proteolytic activity despite supplementing with $\mathrm{CaCl}_{2}$ (data not shown).

\section{Extension of the time of growth}

The target of this study was to increase the production of secretion protein by modification of growth conditions and the parameters involved in the NICE system. Therefore, the next step of this study was verification of the protein expression (proteolitic activity) of $L$. lactis pNZ45subC and subsequently supplementation with an additional source of nutrients. Since it was shown that adding lactose as a carbon source did not significantly increased protein yield (Mierau et al. 2005a), first we decided to measure the rate of glucose utilization by L. lactis during the growth. Measuring glucose concentration, we have found that most of $0.5 \%$ glucose is utilized within a few hours and consequently the growth of cells slows down (data not shown). Therefore, we decided to supply additional nutrients, glucose as a source of carbon and casitone as a source of nitrogen, in the end of logarithmic phase growth. To this end, the overnight culture L. lactis pNZ45subC was inoculated into fresh GM17 (the start $\mathrm{OD}_{600}$ 0.1) medium supplemented with $0.5 \%$ glucose, $5 \mu \mathrm{g} \mathrm{mL} \mathrm{m}^{-1}$ chloramphenicol, $0.5 \mathrm{mM} \mathrm{CaCl}_{2}$, and 10000 diluted NZ9700 supernatant. After 4 hours, the cultures were supplemented with glucose $(0.5 \%)$ and casitone $(0.1 \%)$. As a control, the induced L. lactis pNZ45subC culture without additional nutrients was used. The proteolytic activity was measured 4, 6 and 24 hours after induction. Surprisingly, we did not observe differences in proteolytic activity between cultures (data not shown).

Subsequently, the same experiment for the culture induced at the midlog phase growth was performed. The culture was grown under the same conditions as described before. When the culture pNZ45subC reached $\mathrm{OD}_{600}$ 0.6, it was induced with 10000 diluted NZ97000 supernatant. Two hours after induction, the culture was supplemented with glucose and casitone to final concentrations $0.5 \%, 0.1 \%$, respectively. As a control the induced L. lactis pNZ45subC culture without additional nutrients was used. The proteolytic activity was measured 2, 3, 4 and 24 hours after induction. The results are shown in Figure 5. Interestingly, the activity $2 \mathrm{~h}$ after induction was on the same level in both cultures; however, already in the next 2 hours it increased in the culture supplemented with additional nutrients. According to previous experiments, the highest activity was observed after 24 hours. Moreover, the activity in the supplemented culture was $30-40 \%$ higher than in the control.

Next, we wanted to determine if our system for heterologous secreted protein production might be employed at a larger scale. Therefore an experiment with a $1.5 \mathrm{~L}$ batch fermentation was performed. The strain was grown in GM17 medium supplemented with 10\% milk and $5 \mu \mathrm{g} \mathrm{mL} \mathrm{m}^{-1}$ chloramphenicol. We established $\mathrm{pH}$, concentration of glucose, fermentation temperature, the time point of induction and the nisin concentration necessary for optimal SubC induction. The results obtained in bioreactor confirmed the experiments performed at the laboratory scale. L. lactis carrying pNZ45subC plasmid was induced at the inoculation point with the supernatant of NZ9700. Again, the highest proteolytic activity was observed 24 hours after induction, moreover, it remained stable in next coming 24 hours (Figure 6). The addition of extra nutrients to the culture induced at the start point did not increased proteolytic activity of the supernatant. In summary, the production of SubC was increased and the secreted protein remains stable, which simplifies the purification of this protease.

\section{Discussion}

Gram-positive GRAS bacteria are recently investigated to replace host organisms such as Escherichia coli, for some pharmaceutical or food grade proteins production. Although different Bacillus species are employed in the industry they might cause problems in the production process, such as spore formation or in some strains toxins production (Pedersen et al. 2002; Salkinoja-Salonen et al. 1999). Therefore, a good option for food-relevant 


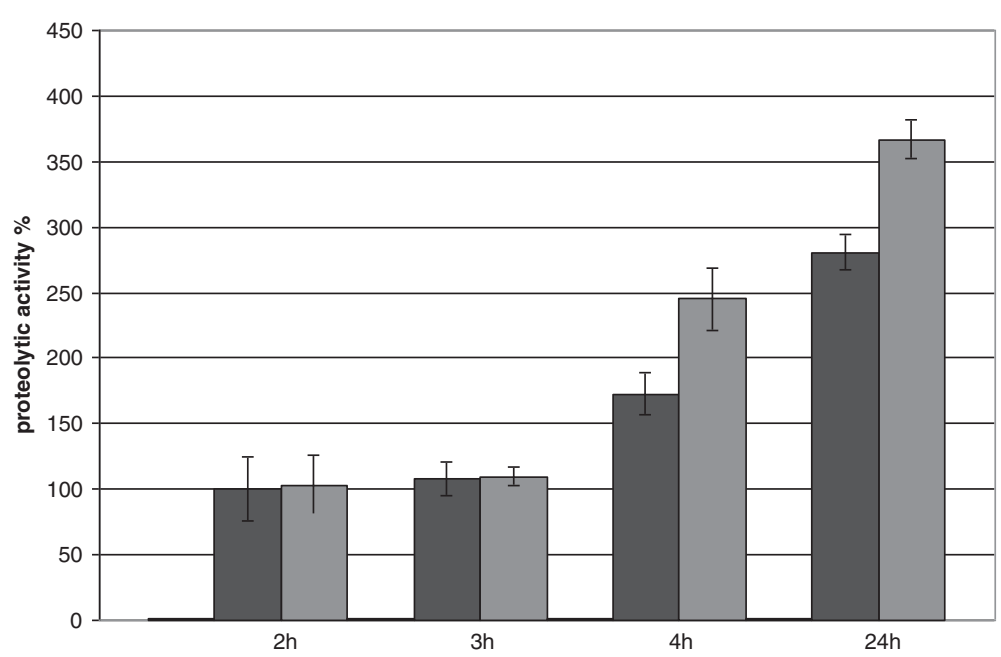

Figure 5 The proteolytic activity of L. lactis carrying pNZ45subC. The cultures were grown in GM17 medium supplemented with $0.5 \mathrm{mM}$ $\mathrm{CaCl}_{2}$ and $5 \mu \mathrm{g} \mathrm{mL}^{-1}$ of chloramphenicol. The cultures were induced at $\mathrm{OD}_{600}$ 0.7. The samples were taken as indicated on the picture: 2, 3, 4 and 24 hours after induction with 10000 NZ9700 supernatant. Pale gray bars- strain without induction (values below 1). Black bars- control strain without additional nutrients. Dark gray bars- the strain supplemented with an additional nutrients in two hours after induction. All data are mean values of three independent experiments; error bars indicate standard deviation.

proteins production is lactic acid bacteria (LAB) such as Lactococcus lactis (Hugenholtz 2008). They are widely used in industrial fermentations, so much information is available about nutrient requirements, growth conditions etc. Moreover, for $L$. lactis the genome sequence has been published (Wegmann et al. 2007) and many genetic tools have been developed for LAB, which simplifies the usage of these microorganisms as a cell factory. Additionally they do not require aeration and only very limited mixing that significantly reduces production and reactor costs. One of the most popular expression systems in L. lactis is the NICE system (Mierau \& Kleerebezem 2005; Kuipers et al. 1995).
In this study, we present the modification of the NICE system for heterologous secretion protease production in L. lactis, with possible usage at industrial scale. We used two different NICE vectors; we compared different ranges of nisin A concentration for induction and nutrient requirements. For that purpose, the $s u b C$ gene encoding $B$. licheniformis extracellular alkaline protease was cloned downstream of the strong inducible promoter nisA and ranges of diluted supernatant of NZ9700 L. lactis (nisin producer) were used for the induction of secreted enzyme production. In this study, we optimized the growth and NICE- related parameters. Strikingly, laboratory strains of $L$. lactis possess only

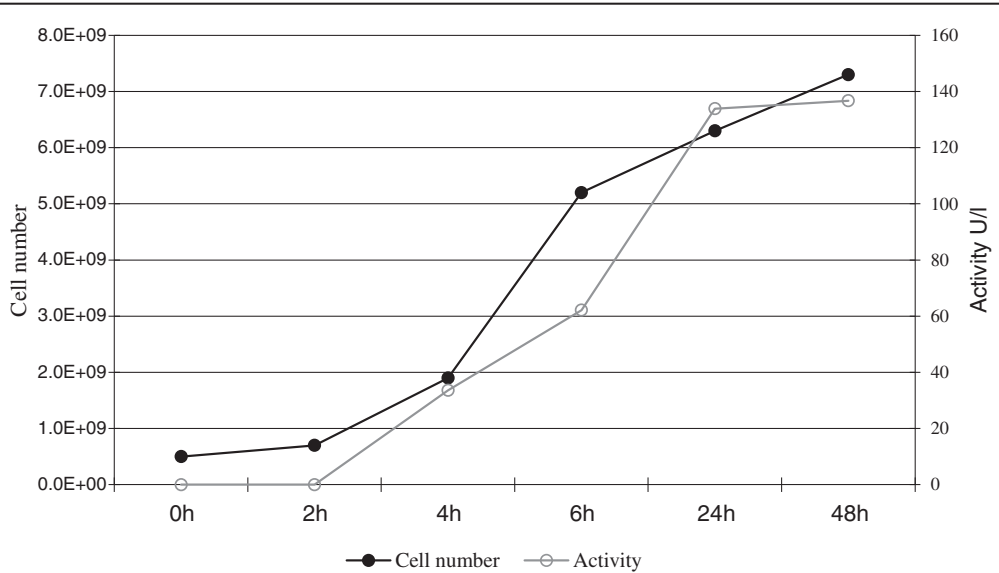

Figure 6 The proteolytic activity of L. lactis carrying pNZ45subC in $\mathbf{5}$ L bioreactor (working volume $1.5 \mathrm{~L}$ ). The culture was grown in GM17 medium supplemented with $10 \%$ milk and $5 \mu \mathrm{g} \mathrm{mL} \mathrm{L}^{-1}$ of chloramphenicol. The culture was induced at $\mathrm{OD}_{600} 0.2$. The samples were taken as indicated on the picture. 
one exported housekeeping protease, HtrA involved in protein quality control at the cell surface. Moreover, HtrA is responsible for clearing anomalous proteins from the surface, and is induced under several stress conditions (Morello et al. 2008).

The expression of heterologous protease might be lethal for L. lactis, however it was recently shown that the use of SP Usp45 also allows the secretion of bacteriocins which are toxic for cells (Borrero et al. 2009). Therefore to avoid toxicity we added signal peptide of Usp45 to secrete SubC via Sec transporters. Indeed higher protease expression and accumulation within the cell resulted in growth inhibition (data not shown). Here we observed that the addition of lactococcal SP usp45 to the native signal peptide of SubC leads to better secretion, and more importantly, secreted protein remains stable, since both signal peptides are properly cleaved during protein translocation to the medium. Interestingly, a construct with two signal peptides results in higher accumulation of the protease in extracellular medium.

Subsequently, we investigated the media preferences for optimal protein production. The previously described medium (Mierau et al. 2005a) did not increase the protein level. In contrast, medium supplementation with calcium chloride resulted in superior activity of protease in the extracellular environment. Interestingly, we have also noticed that supplementing GM17 medium with other two positive ions, results in elevated proteolytic activity of SubC producer, nonetheless the highest activity was observed in samples supplemented with 0.5 $\mathrm{mM} \mathrm{CaCl}$. After establishing the medium preferences for SubC production, we tested various induction time points. Hitherto, the strains carrying overexpression constructs were induced at the midlog growth phase or at high OD (Mierau et al. 2005a; Maischberger et al. 2010) although we have not confirmed the reports showing the results of induction at start point. To this end, the overnight cultures of L. lactis carrying pNZ45subC or pNZ48subC were inoculated into fresh medium, supplemented as aforementioned, and induced at $\mathrm{OD}_{600}$ 0.1 and 0.6 and with various ranges of NZ9700 supernatant. The samples were tested for proteolytic activity 24 hours after induction. We did not observe significant differences in the proteolytic activity between all samples, which might suggest that the level of functional SubC protease was the same in all cultures. In contrast to other reports (Berlec et al. 2008), we did not observe a correlation between increasing OD and protein production. One of the most interesting parts of this phenomenon is the problem of the stability/activity of SubC in the extracellular environment. Strikingly, the SDS-PAGE data showed that the level of protein production in various cultures was unchanged; however the proteolytic activity was different. This could result from various proportions of mature versus immature protease as seen from SubC amino acid sequence determination. Noticeably, the overproduction of protein might also cause stress responses and consequently degradation of the target protein in the cells (Thumm \& Gotz 1997).

We compared different nisinA concentrations for L. lactis induction. The studied nisin concentration range was from 0.1 to $10.0 \mathrm{ng} \mathrm{mL}^{-1}$ and the highest proteolytic activity was obtained when $1 \mathrm{ng} \mathrm{mL}-1$ of nisinA or 10000 - 20000 diluted supernatant of L. lactis NZ9700 was used. In comparison, nisin concentration in published data varies from 0.5 to $40 \mathrm{ng} \mathrm{mL}^{-1}$ (Mierau et al. 2005b). Thus induction during inoculation of the bioreactor enables reduction of the inducer amount and simplifies the production process. One of the most interesting issues of this study was an extension of the logarithmic phase growth of $L$. lactis, since during this phase the highest activity was observed.

Initial experiments showed that L. lactis utilizes most of the $0.5 \%$ glucose present in GM17 medium. Consequently, the next step was to supply more nitrogen and carbon sources. The cultures were induced at $\mathrm{OD}_{600} 0.6$, the additional nutrients were added in two hours after induction. Interestingly, we observed increased proteolytic activity already 2 hours after supplementing with nutrients. The differences between the target strain and the control were between 30-40\%, the highest differences were observed in 6 hours after induction, and remained stable up to $24^{\text {th }}$ hour after inductions.

In summary, we optimized the NICE expression system for heterologous secretion protease production. The use of a GRAS expression host for secreted enzyme production will make it possible to use these proteins much more easily and economically, than in the case of intracellular production. The described expression system might be used for industrial production of rennet or direct application of such strain in dairy.

\section{Competing interests}

The authors declare that they have no competing interests.

\section{Authors' contributions}

AMM carried out the molecular genetic studies, performed the experiments, analyzed the data, wrote the manuscript. AK analyzed the data, drafted the manuscript. AM performed the experiments, analyzed the data, drafted the manuscript. MP performed the experiments, analyzed the data, participated in the sequence alignment, drafted the manuscript. M $Ł$ Contributed reagents/materials/analysis tools, analyzed the data, wrote the manuscript. All authors read and approved the final manuscript.

\section{Acknowledgements}

We thank Oscar P. Kuipers for the gift of L. lactis vectors pNZ8048 and L. lactis NZ9700, and Katarzyna Bednarz for technical support.

This work was supported by grant KB/48/13639/IT1-B/U/08 from the Polish National Centre for Research and Development and EU POIG.01.01.02-00016/2008. 


\section{Author details}

${ }^{1}$ Department of Biotechnology and Food Microbiology, Wrocław University of Environmental and Life Sciences, Chełmońskiego 37/41, Wrocław 51-630, Poland. 'Department of Biotransformation, Faculty of Biotechnology, University of Wroclaw, Przybyszewskiego 63-77, Wroclaw 51-148, Poland. ${ }^{3}$ Faculty of Chemistry, Wrocław University of Technology, Gdańska 7/9, Wrocław 50-344, Poland.

Received: 4 September 2012 Accepted: 8 November 2012 Published: 29 November 2012

\section{References}

Aehle W, Bott R, Graycar T, Flickinger MC (2009) Proteolytic Cleavage, Reaction Mechanisms. Encyclopedia of Industrial Biotechnology, John Wiley \& Sons, Inc

Berlec A, Strukelj B (2009) Large increase in brazzein expression achieved by changing the plasmid/strain combination of the NICE system in Lactococcus lactis. Lett Appl Microbiol 48:750-755

Berlec A, Tompa G, Slapar N, Fonovic UP, Rogelj I, Strukelj B (2008) Optimization of fermentation conditions for the expression of sweet-tasting protein brazzein in Lactococcus lactis. Lett Appl Microbiol 46:227-231

Blatny JM, Ertesvag H, Nes IF, Valla S (2003) Heterologous gene expression in Lactococcus lactis; expression of the Azotobacter vinelandii algE6 gene product displaying mannuronan C-5 epimerase activity. FEMS Microbiol Lett 227:229-235

Bolotin A, Wincker P, Mauger S, Jaillon O, Malarme K, Weissenbach J, Ehrlich SD, Sorokin A (2001) The complete genome sequence of the lactic acid bacterium Lactococcus lactis ssp. lactis IL1403. Genome Res 11:731-753

Borrero J, Jimenez JJ, Gutiez L, Herranz C, Cintas LM, Hernandez PE (2999) Use of the usp45 lactococcal secretion signal sequence to drive the secretion and functional expression of enterococcal bacteriocins in Lactococcus lactis. Appl Microbiol Biotechnol 89:131-143

Briedigkeit L, Frömmel C (1989) Calcium ion binding by thermitase. FEBS Lett 253:83-87

Cibik R, Tailliez P, Langella P, Chapot-Chartier MP (2001) Identification of Mur, an atypical peptidoglycan hydrolase derived from Leuconostoc citreum. Appl Environ Microbiol 67:858-864

Gupta R, Beg QK, Lorenz P (2002) Bacterial alkaline proteases: molecular approaches and industrial applications. Appl Microbiol Biotechnol 59:15-32

Hirata J, Ariese F, Gooijer C, Irth H (2003) Continuous-flow protease assay based on fluorescence resonance energy transfer. Anal Chim Acta 478:1-10

Hugenholtz J (2008) The lactic acid bacterium as a cell factory for food ingredient production. Int Dairy J 18:466-475

Jacobs MF (1995) Expression of the subtilisin Carlsberg-encoding gene in Bacillus licheniformis and Bacillus subtilis. Gene 152:69-74

Kleerebezem M, Quadri LE (2001) Peptide pheromone-dependent regulation of antimicrobial peptide production in Gram-positive bacteria: a case of multicellular behavior. Peptides 22:1579-1596

Kuipers OP, Beerthuyzen MM, de Ruyter PG, Luesink EJ, de Vos WM (1995) Autoregulation of nisin biosynthesis in Lactococcus lactis by signal transduction. J Biol Chem 270:27299-27304

Kuipers OP, de Ruyter PGGA, Kleerebezem M, de Vos WM (1998) Quorum sensing-controlled gene expression in lactic acid bacteria. J Biotechnol 64:15-21

Kumar CG, Takagi H (1999) Microbial alkaline proteases: from a bioindustrial viewpoint. Biotechnol Adv 17:561-594

Kunji ER, Slotboom DJ, Poolman B (2003) Lactococcus lactis as host for overproduction of functional membrane proteins. Biochim Biophys Acta 1610:97-108

Leenhouts KJ, Venema G (1993) Plasmids, a practical approach. Oxford University Press, Oxford, United Kingdom

Maischberger T, Mierau I, Peterbauer CK, Hugenholtz J, Haltrich D (2010) High-level expression of Lactobacillus beta-galactosidases in Lactococcus lactis using the food-grade, nisin-controlled expression system NICE. J Agric Food Chem 58:2279-2287

Mierau I, Kleerebezem M (2005) 10 years of the nisin-controlled gene expression system (NICE) in Lactococcus lactis. Appl Microbiol Biotechnol 68:705-717

Mierau I, Olieman K, Mond J, Smid EJ (2005a) Optimization of the Lactococcus lactis nisin-controlled gene expression system NICE for industrial applications. Microb Cell Fact 4:16

Mierau I, Leij P, van Swam I, Blommestein B, Floris E, Mond J, Smid EJ (2005b) Industrial-scale production and purification of a heterologous protein in
Lactococcus lactis using the nisin-controlled gene expression system NICE: the case of lysostaphin. Microb Cell Fact 4:15

Miyoshi A, Poquet I, Azevedo V, Commissaire J, Bermudez-Humaran L, Domakova E, Le Loir Y, Oliveira SC, Gruss A, Langella P (2002) Controlled production of stable heterologous proteins in Lactococcus lactis. Appl Environ Microbiol 68:3141-3146

Morello E, Bermudez-Humaran LG, Llull D, Sole V, Miraglio N, Langella P, Poquet I (2008) Lactococcus lactis, an efficient cell factory for recombinant protein production and secretion. J Mol Microbiol Biotechnol 14:48-58

Morita Y, Hasan Q, Sakaguchi T, Murakami Y, Yokoyama K, Tamiya E (1998) Properties of a cold-active protease from psychrotrophic Flavobacterium balustinum P104. Appl Microbiol Biotechnol 50:669-675

Nouaille S, Ribeiro LA, Miyoshi A, Pontes D, Le Loir Y, Oliveira SC, Langella P, Azevedo V (2003) Heterologous protein production and delivery systems for Lactococcus lactis. Genet Mol Res 2:102-111

Olempska-Beer ZS, Merker Rl, Ditto MD, DiNovi MJ (2006) Food-processing enzymes from recombinant microorganisms-a review. Regul Toxicol Pharmacol 45:144-158

Pedersen PB, Bjornvad ME, Rasmussen MD, Petersen JN (2002) Cytotoxic potentia of industrial strains of Bacillus sp. Regul Toxicol Pharmacol 36:155-161

Platteeuw C, van Alen-Boerrigter I, van Schalkwijk S, de Vos WM (1996) Food-grade cloning and expression system for Lactococcus lactis. Appl Environ Microbiol 62:1008-1013

Rao MB, Tanksale AM, Ghatge MS, Deshpande W (1998) Molecular and biotechnological aspects of microbial proteases. Microbiol Mol Biol Rev 62:597-635

Saeki K, Ozaki K, Kobayashi T, Ito S (2007) Detergent alkaline proteases: enzymatic properties, genes, and crystal structures. J Biosci Bioeng 103:501-508

Salkinoja-Salonen MS, Vuorio R, Andersson MA, Kampfer P, Andersson MC, Honkanen-Buzalski T, Scoging AC (1999) Toxigenic strains of Bacillus licheniformis related to food poisoning. Appl Environ Microbiol 65:4637-4645

Siezen RJ, Bayjanov J, Renckens B, Wels M, Van Hijum SA, Molenaar D, Van Hylckama Vlieg JE (2010) Complete genome sequence of Lactococcus lactis subsp. lactis KF147, a plant-associated lactic acid bacterium. J Bacteriol 192:2649-2650

Terzaghi BE, Sandine WE (1975) Improved medium for lactic streptococci and their bacteriophages. Appl Microbiol 29:807-813

Thumm G, Gotz F (1997) Studies on prolysostaphin processing and characterization of the lysostaphin immunity factor (Lif) of Staphylococcus simulans biovar staphylolyticus. Mol Microbiol 23:1251-1265

Tremacoldi CR, Watanabe NK, Carmona EC (2004) Production of Extracellular Acid Proteases by Aspergillus Clavatus. World J Microbiol Biotechnol 20:639-642

van Asseldonk M, de Vos WM, Simons G (1993) Functional analysis of the Lactococcus lactis usp45 secretion signal in the secretion of a homologous proteinase and a heterologous alpha-amylase. Mol Gen Genet 240:428-434

von der Osten C, Branner S, Hastrup S, Hedegaard L, Rasmussen MD, Bisgard-Frantzen H, Carlsen S, Mikkelsen JM (1993) Protein engineering of subtilisins to improve stability in detergent formulations. J Biotechnol 28:55-68

Wegmann U, O'Connell-Motherway M, Zomer A, Buist G, Shearman C, Canchaya C, Ventura M, Goesmann A, Gasson MJ, Kuipers OP, van Sinderen D, Kok J (2007) Complete genome sequence of the prototype lactic acid bacterium Lactococcus lactis subsp. cremoris MG1363. J Bacteriol 189:3256-3270

doi:10.1186/2193-1801-1-54

Cite this article as: Mirończuk et al:: Production of the Bacillus licheniformis SubC protease using Lactococcus lactis NICE expression system. SpringerPlus 2012 1:54. 